\title{
ELECTRONIC CONTROLS FOR THE TETRAPLEGIC (POSSUM) (PATIENT OPERATED SELECTOR MECHANISMS-P.O.S.M.)
}

\author{
By R. G. Maling and D. C. Clarkson \\ Electro-Mechanical Laboratory of the Research Department, National Spinal Injuries Cenire, \\ Stoke Mandeville Hospital, Aylesbury, Bucks, England
}

\section{INTRODUCTION}

THE increasing nursing and medical skills have produced the new situation in which the substantially totally paralysed are being kept alive and given life expectancies approaching the normal span. This situation provides both a challenge and responsibility in that the personalities of the patients remain normal or are even enhanced by reason of the struggle to make sense of life in such circumstances. The challenge is to provide them with forms of control over their immediate environment with effective communication, both in the writing and speaking sense, and to endeavour to provide them with a means of livelihood through the achieving of a worthwhile skill.

\section{PRINCIPLES OF 'BY-PASS' CONTROLS}

When the severity of the lesion produces a substantially complete paralysis, as a result of high cervical spinal cord injury or high poliomyelitis, the sheer mass of conventionally powered and applied prosthetic appliances becomes vast and the control problem becomes too complex. The work to be described in this article constitutes a third group of prostheses, which may be called 'By-pass' Controls in that they deliberately by-pass the site of the disability and take their control from the little of what is left of normal innervation and muscular power in the section above the lesion. A control site should preferably have the following characteristics: (a) normal innervation $(b)$ its muscular function must be unaffected by the remainder of the paralysis $(c)$ it should be capable of sustained use $(d)$ it should be capable of acceleration. In tetraplegic patients at and above $\mathrm{C}_{5}$ or in high polio patients with only the head available, the mouth would seem to fulfil the above requirements remarkably well. With the appropriate electronic circuitry, the mouth can give a remarkably efficient and comprehensive control over both the immediate environment and over any electro-mechanical or electronic equipment which is normally worked by push buttons or purely electrical switching.

\section{DEVELOPMENT AND TECHNIQUES OF POSSUM}

The work described in this paper was started in I960 by the authors; it was continued and developed at the Research Department of the National Spinal Injuries Centre with a grant provided by the Polio Research Fund.

The problem of a form of control for such a severely disabled person was brought forcibly to our attention in a 33 year old tetraplegic patient, Ian Pritchard, who was admitted to this Centre from Southern Rhodesia three weeks after an accident while water skiing. The patient, formerly an outstanding sportsman, soldier and sailor, sustained a fracture-dislocation of the fifth cervical vertebra 
resulting in a tetraplegia, incomplete below $\mathrm{C}_{4}$ and complete below $\mathrm{C}_{5} / 6$. The initial treatment of the fracture-dislocation in Rhodesia was by skull traction with open reduction and tracheostomy. There was no recovery of the tetraplegia-in fact, on admission to this Centre the patient had great difficulty in extending his head, when placed in prone position, due to profound weakness of his neck muscles as a result of the operation.

Two pressure sores over the posterior iliac spine started two days after the accident.

On admission to this Centre, he had only very weak function of the biceps and deltoid on the left side-otherwise, all voluntary function in both upper limbs was abolished. He tended to feel faint when moved suddenly. The sores needed conservative followed by surgical treatment and eventually healed. The bladder and bowels were trained and the catheter abandoned, once the severe bladder infection was controlled and a satisfactory automatic function of the bladder established. This patient's morale was excellent from the start and the completeness of his personality above the neck contrasted starkly with his complete uselessness below. Above the neck was interest, good sense of humour and concernbelow, there was nothing but spinal automatism.

This situation provided the determination that such a personality ought to be able to exert some degree of control over his environment. All that he had, in fact, to communicate with the outside world was a Metropolitan Police whistle suspended by a piece of string just above his lips.

Recalling that the patient had one mouth function in the shape of control over a whistle, we examined the force required to blow a whistle. This required a considerable effort for such a patient, a flow rate of one litre per second at a pressure of $20 \mathrm{~mm}$. of mercury. This might be possible where diaphragm breathing remains, but is clearly impossible where there is no voluntary breathing at all. Our own experiments showed that if no flow of air is required, then the mouth can produce a good sustained pressure or a good sustained suction independent of any breathing occurring through the nose. It is well known that in such patients the front of the tongue can close the front of the mouth so that the mouth acts as a separate physiological unit, independent of any respiratory function.

From a purely engineering point of view, the mouth turns out to be a remarkably good pneumatic controller; the average mouth can produce a pressure of $60 \mathrm{~mm}$. of mercury and a suction of $100 \mathrm{~mm}$. of mercury. These figures are for isometric (no flow) conditions. In practice a volume change of $\pm \mathrm{I} \mathrm{ml}$. accompanies the desired pressure change, i.e. of the order of O.I per cent. of the Tidal Volume.

How then to control? If advantage is taken of the electrical conductivity of mercury and contact wires sealed into the Manometer tube above the stationary level of the mercury, the indicator becomes a controller when the mercury level is raised to that of the contact wires (fig. I). If a small amount of electricity is allowed to pass through the mercury and then through the coil of a relay, we can immediately switch a Kilowatt of electricity or its energy equivalent of more than one horse-power. This is a power amplification factor of some $I, 000,000$ to $I$. It is useful to choose a type of relay which only requires a short pulse of electricity to make it come on and which will then stay on until another short pulse makes it go off, i.e. the mechanically-latching, or two-step relay.

We now have two control parameters. How then to obtain more functions? If we can no longer discriminate with respect to position, which is what is happening 




FIG. I

Mercury Manometer and first mercury switch.

when we physically choose one ordinary electric switch rather than another, the only other dimension available in this continuum is time. We can make use of this by letting our first electrical contact start a rotary switch (fig. 2). We could do this with the mercury manometer, but its mechanical equivalent in the form of a diaphragm operated micro-switch is more practical.

The range of diaphragm switches which is commercially available extends down to the extremely sensitive differential of $0.1 \mathrm{~mm}$. of mercury i.e. the switch will operate on a pressure change of $0.1 \mathrm{~mm}$. of mercury.

The practical control range of any energy system may be considered to lie in the range 5-70 per cent. of the output range of that system, with human physiological systems preferring to work in the 2-20 per cent. range of maximum and with the sustained work capacity occurring the 2-5 per cent. range. Therefore, where the average mouth pressure/suction is $60 / 100 \mathrm{~mm}$. of mercury, a switch was chosen having a differential of $3 \mathrm{~mm}$. of mercury. So the application of light sustained suction will cause the rotary switch to pass over a bank of some ten contacts. If the 


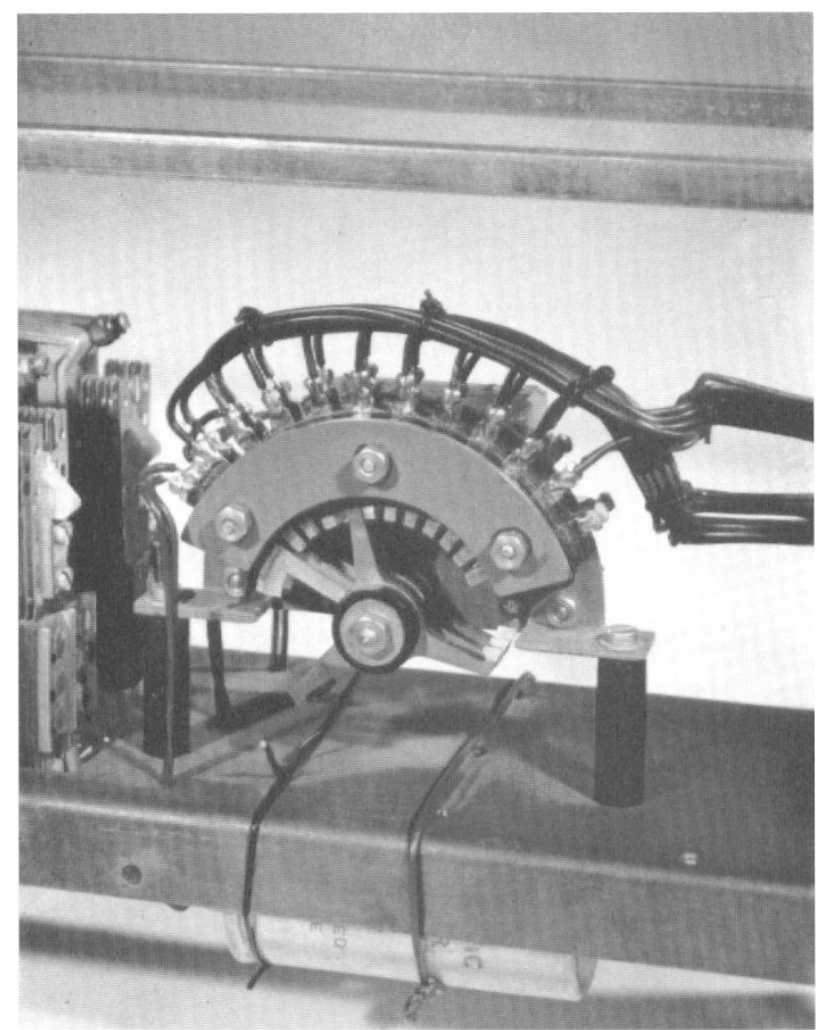

FIG. 2

Selector used in the first prototype giving control over ten functions.

suction is released at any given position, a power relay (mechanically latching) corresponding to that position will switch on or off whatever electrical circuit is connected to it.

This principle is embodied in the Possum Multipurpose Control which provides control over any ten on/off electrical functions such as those of Bell, Light, Radio, Page-Turner, Room Heater, Electrical Blanket, Telephone, Television, Respirator Change etc. (fig. 3).

With all the functions off, each panel of the indicator glows green. As the rotary switch starts, the white lights come on to show the control position (fig. 4). If the suction is released at any position lit by the white light, that function is then switched-first time on, second time off. The 'Bell' is the only exception to this; as it is required to be on for a short time it is switched off automatically after I to 5 seconds.

At the start of the project it was decided that the least possible equipment should need to be very close to the patient, preferably only the control tube to the mouth. The telephone posed a special problem. The ordinary hand-set could be 


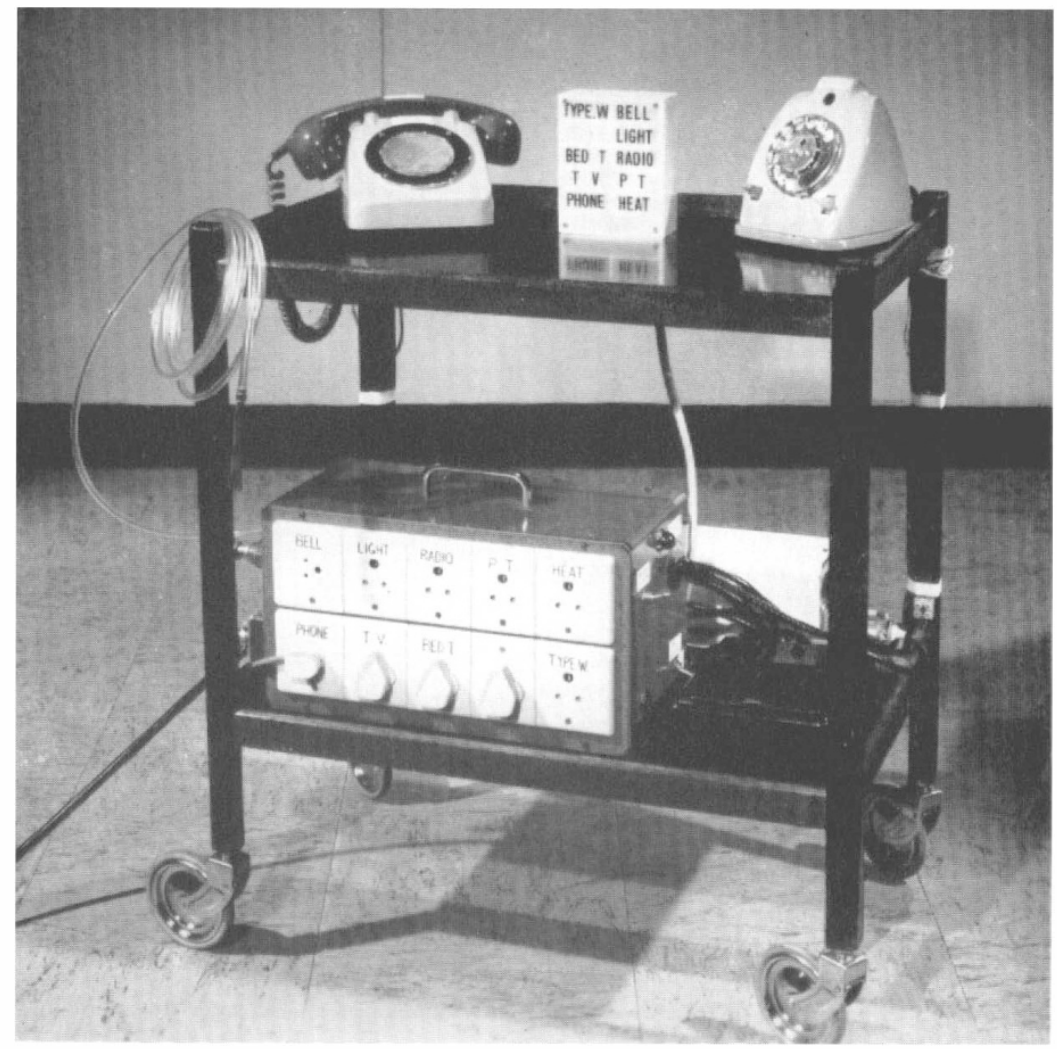

FIG. 3

First general-purpose control complete with indicator and loud-speaking telephone.

fixed permanently in position near to the person's mouth, or it could be arranged to be swung into position when a call was required, or a loudspeaking version could be used which would only require the microphone to be in proximity to the person.

Fortunately for the project the Loudspeaking Telephone No. I was in the advanced prototype stage, and when the Post Office was approached, they gave magnificent assistance. A circuit was prepared, whereby the switching involved in lifting the normal hand-set off its rest could be duplicated by a small relay box, a small microphone at the end of a flexible lead placed near to the person's mouth and an automatic sender provided to dial the necessary ' $O$ ' or ' 100 ' where the exchange was an automatic one. When the position 'Telephone' is obtained on the indicator, the Possum control obtains a line, waits for dialling tone and then dials ' $O$ ' or ' 100 ', the operator's voice comes out of the loudspeaker beside the person and he will ask for the number through a small microphone fixed near to his mouth. At the end of the call he merely repeats the obtaining of the position 'Telephone' which closes the line. For an incoming call the selection procedure is the same; the ringing current is used to prevent the automatic dialler from pulsing.

The Post Office has a recognised prefix 'Special Assistance', if this is said 


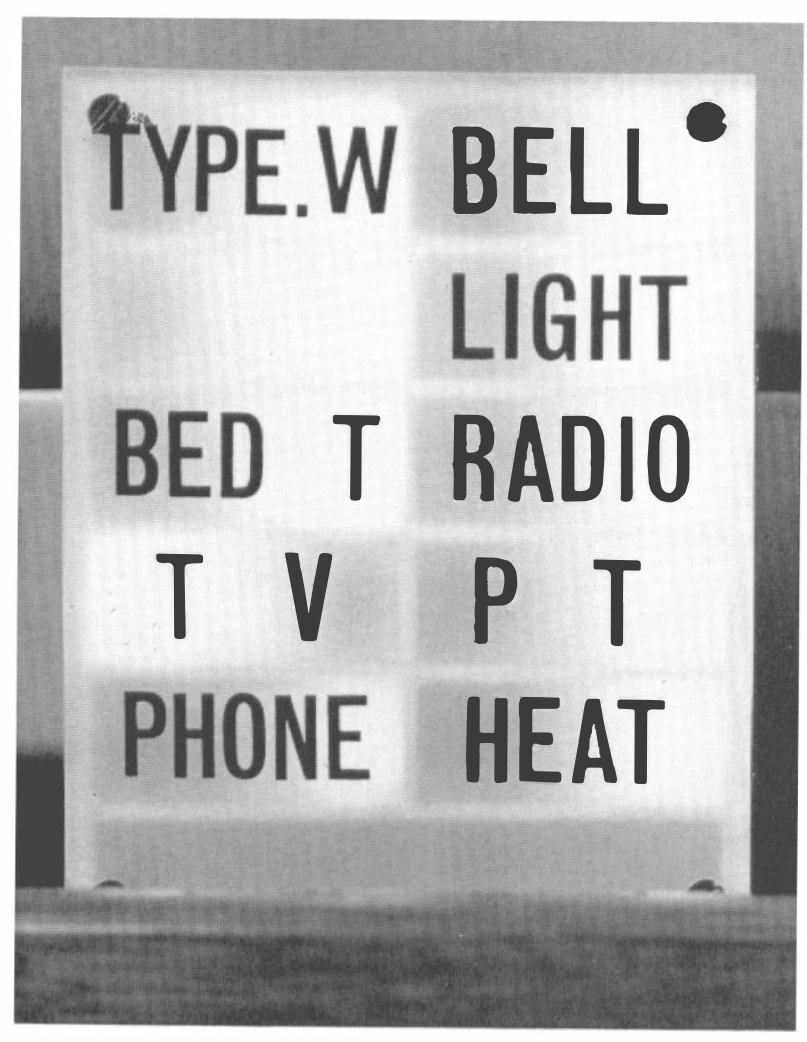

FIG. 4

Enlargement of Indicator Panel shown in Figure 3.

before giving the required number the exchange will not query the request for a local number which would normally be dialable.

The early experimental work in conjunction with the Post Office has now resulted in a complete system bearing the title 'Loudspeaking Telephone No. 5, i.e. Loudspeaking Telephone for Paralysed Subscribers'.

Going back for the moment to the mercury manometer control, it was mentioned that this illustrated the two control parameters available from the mouth, namely Suck and Puff. So far we have only used Suck to obtain more than one function. With the second parameter it is now possible not merely to double the number of functions controllable, but to square them, in fact, literally to extract from a square. Referring to the Possum Typewriter Grid I (fig. 5) it will be seen that 'Suck' is along the bottom row of figures or X ordinate and 'Puff' along the vertical row of figures, or $\mathrm{Y}$ ordinate.

To extract any letter, say $S$, light sustained suction is applied to the tube until the control has clicked or pulsed (the audio signal can be varied to suit individual preference both in type and frequency) three times, thus obtaining the third column which contains S; then light, sustained pressure is applied until the control has clicked (or pulsed) twice, thus obtaining the second position within that column. 
ELECTRONIC CONTROLS FOR THE TETRAPLEGIC (POSSUM)

POSSUM - TYPEWRITER GRID 1

\begin{tabular}{|c|c|c|c|c|c|c|}
\hline 8 & $\begin{array}{l}* \\
2\end{array}$ & $\begin{array}{l}\& \\
7\end{array}$ & ', & TAB & $\mathbf{B} / \mathbf{S}$ & TRANS. \\
\hline 7 & $\mathbf{K}$ & $\mathbf{Q}$ & $\begin{array}{l}\$ \\
6\end{array}$ & $\begin{array}{l}\text { ) } \\
\frac{1}{4}\end{array}$ & $\begin{array}{l}\% \\
\frac{1}{2}\end{array}$ & $\mathbf{Z}$ \\
\hline 6 & $\mathbf{w}$ & $\mathbf{v}$ & J & $\begin{array}{l}E \\
5\end{array}$ & $\begin{array}{l}\text { ( } \\
9\end{array}$ & $\begin{array}{l}+ \\
=\end{array}$ \\
\hline 5 & $\mathbf{U}$ & $M$ & B & $\begin{array}{l}\text { : } \\
\text {; }\end{array}$ & $\begin{array}{l}@ \\
4\end{array}$ & $\begin{array}{l}\frac{3}{4} \\
8\end{array}$ \\
\hline 4 & $\mathbf{R}$ & D & $\mathbf{Y}$ & $\begin{array}{l}? \\
\text { ? }\end{array}$ & $x$ & $\begin{array}{l}1 \\
3\end{array}$ \\
\hline 3 & Caps & $\mathbf{N}$ & C & $\mathbf{F}$ & • & - \\
\hline 2 & $\mathbf{T}$ & $\mathbf{A}$ & $\mathbf{S}$ & $\mathbf{H}$ & $\mathbf{P}$ & G \\
\hline 1 & Space & $\mathbf{E}$ & 0 & $\mathbf{I}$ & $\mathbf{L}$ & Ca. Ret. \\
\hline$R T$ & 1 & 2 & 3 & 4 & 5 & 6 \\
\hline
\end{tabular}

\section{SUCK}

FIG. 5

Control Grid for the first Possum typewriter system.

On release of mouth pressure the letter types. In Figure 6 a high cervical cord lesion patient is shown controlling such a system.

The investigation into the probable speed of the typewriter system was most interesting. It was accepted at the outset that the limitation would be the human 


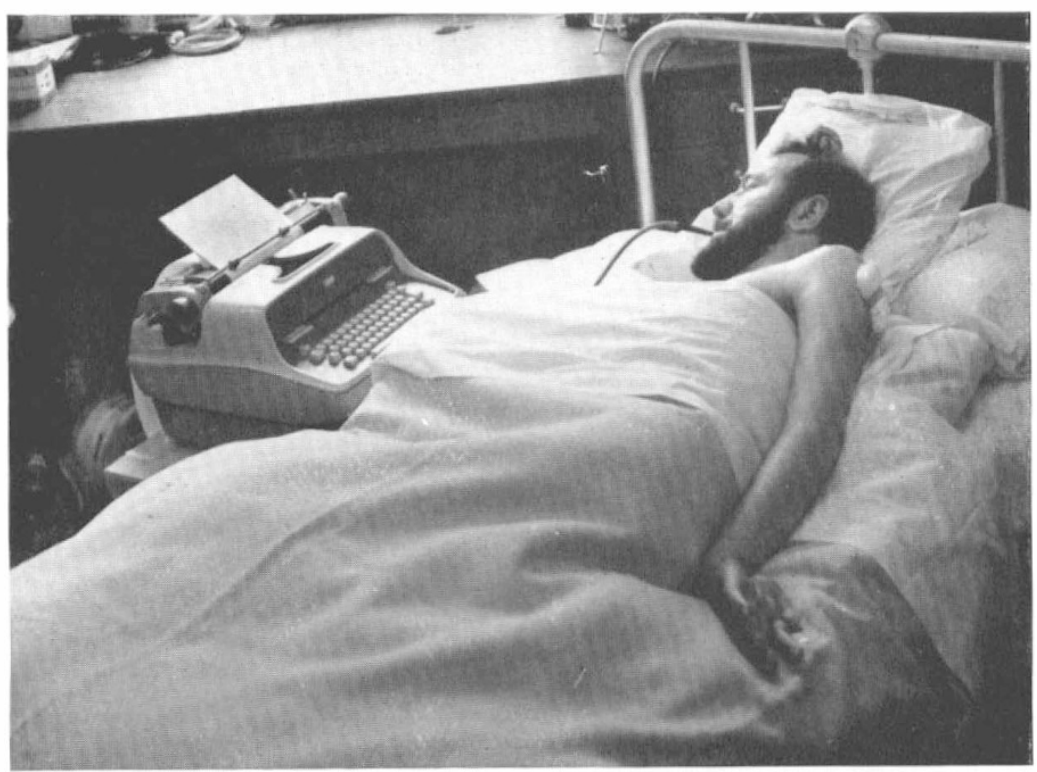

FIG. 6

High-level patient using typewriter system (complete traumatic transection at $\mathrm{C}_{4}$ ).

one. A study of the sense channels suggested that the ear would be far the best input. It has the highest rate of pulse discrimination, it is capable of sustained use and is normally used much less than the eyes. A study of morse-code techniques suggested that the ear can easily be trained to discriminate and act upon pulse trains occurring at up to ten pulses per second. The typewriter control was accordingly provided with eight speeds, the highest at ten pulses per second.

Because of the very considerable skew distribution of the alphabet, the average letter can be extracted from Grid I by monitoring the passage of a total of 4.6 pulses, i.e. an average of 2 on the Suck or X ordinate and an average of 2.6 on the Puff or Y ordinate. Therefore, an average of just over two letters can be extracted, and hence typed, every second, giving a speed for this grid of 26 words per minute. Other grid systems have been devised which may permit the eventual speed to be raised to over one hundred words per minute. In mechanical terms, this means that the selector must move at a top speed, on selection, of ten positions per second. This incidentally, is the same speed as is required to respond to the finger dial of the ordinary telephone.

We would like to emphasise that the development of the systems has been based on the suggestions and comments given by patients using the equipment in both hospital and home environments. A typical selection of the earlier equipment is shown in Figure 7, where a poliomyelitis patient is shown in control. He is looking at the typewriter control grid or code, as previously given in Figure 5. Such a grid or code can be memorised within the course of a few days and may then be discarded altogether. This depends, of course, on the intelligence and personality of the pupil. 


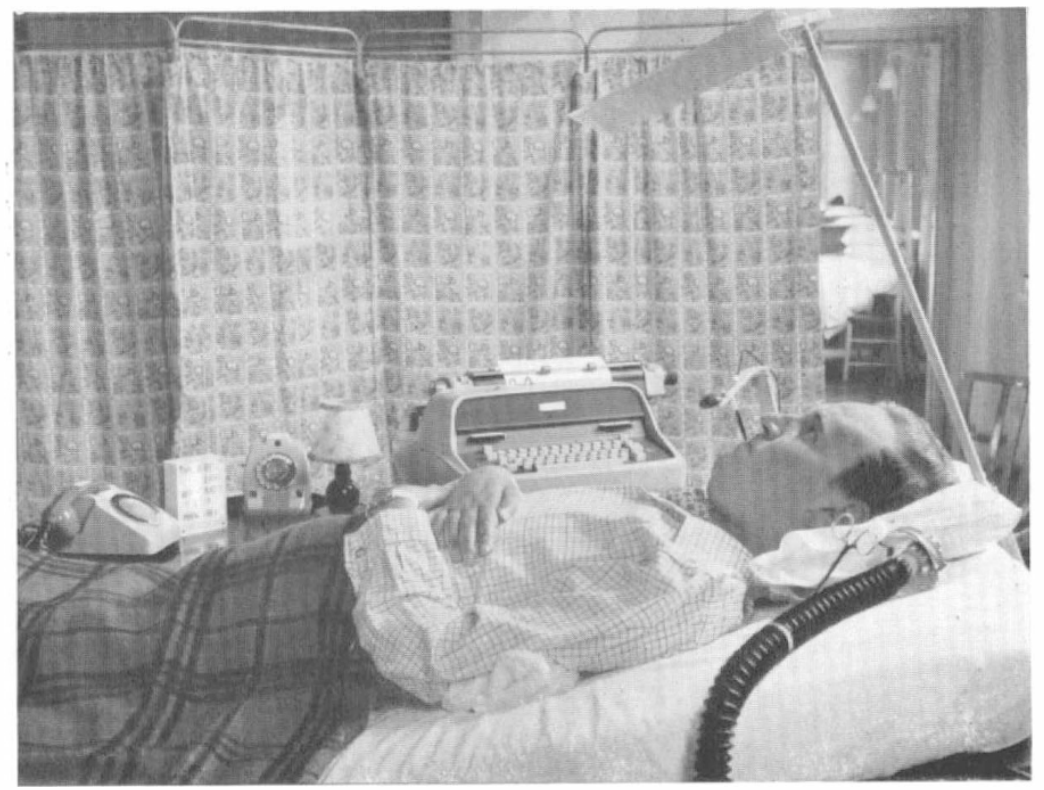

FIG. 7

High-lesion poliomyelitis patient using a typical selection of equipment.

The next development was to give detailed control over those devices which had only been switched on or off in the earlier equipment. A typical indicator for such an improved range of control is shown in Figure 8 and the indicator itself is standing on the new version controller. A more comprehensive indicator is shown in Figure 9 and this will now be described in detail. Our earlier experience had shown the need for two forms of calling, one to be the emergency signal and the other to signify the 'Please come when convenient' type of call. Accordingly, the bell is given as the emergency call and is arranged to stay on until someone comes in response to the call. The buzzer fulfils the second function and merely sounds for a brief few seconds. Both of these functions are obtained by maintaining suction until the white light appears in the desired panel of the indicator and then releasing the suction. The third line of the indicator entitled 'Com.' stands for Communications and is again obtained by maintaining suction until the third panel is illuminated. But now there is a choice between telephone and typewriter and this choice is made by giving sustained pressure until either of these two panels becomes illuminated: Release of the pressure at either of the panels obtains the particular function. The fourth line down gives access to control over the lighting and the three abbreviations stand for a flourescent tubular light, a conventional wall light and an Anglepoise over the bed. The fifth line gives access to a fiveposition electric heater. The first two of these positions give the fan without any heat and positions 3, 4 and 5 add heat progressively to the extent of I, 2 and $3 \mathrm{Kw}$. The sixth line gives control over the radio and the detailed control across the tuning line gives access to the Third, Home and Light programmes. The 'Vol.' at the beginning of the seventh line is a continuation of the radio control and gives a fivestep choice of volume. 


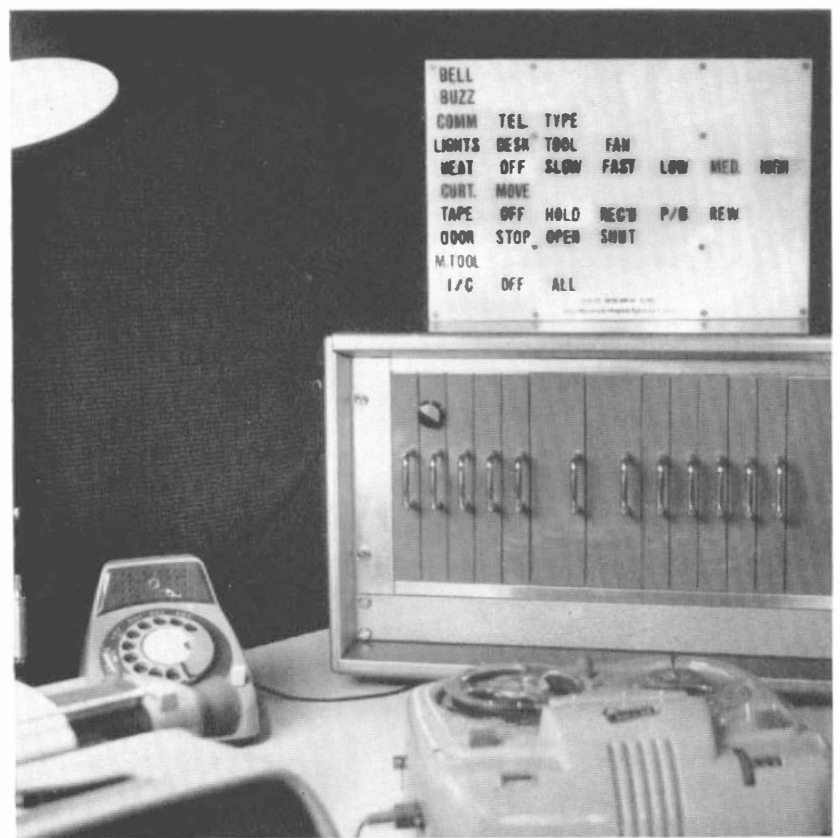

FIG. 8

A later development of the multi-purpose controller with the comprehensive indicator standing on top of the control console.

The eighth line beginning T.V. is the first of some four lines allocated to the detailed control of the chosen television set, the 'Vol., Brill. and Con.' standing for control over Volume, Brilliance and Contrast. In the twelfth line the M.F.P. stands for Micro-film Projector and full control has been given in a surprisingly simple way. By selecting the function 'M.F.P.' itself the projector is switched on; by then using pressure to transfer the control to the 'On' panel the film is advanced as long as the pressure is maintained. The reversal of the film, i.e. the turning back of the pages, is obtained by a repeat selection of the panel 'On'. The thirteenth line gives access to a Tape Recorder and the detailed control gives access to a Hold or Warm-up position, Record, Play-back and Rewind functions. The fourteenth line gives control over a three-heat Electric Blanket. The fifteenth line is shown as giving control over a Respirator. This is a special function for the arrangement where two respirators are set up in parallel, one being on mains supply and the other on battery. These are normally arranged so that if a mains failure occurs the battery operated stand-by takes over immediately. But it can happen occasionally that a mechanical fault takes place in the mains respirator: The patient's control then permits him to change over immediately to the battery operated respirator by switching off the mains power to the mains respirator.

The ' $I / C$ ' of the sixteenth line indicates a five-position control over an intercommunication system, the positions of 'All, Kitchen, Drawingroom, Bedroom and Garden' showing a typical sequence that a patient may choose for use at home. 


\begin{tabular}{|l|c|c|c|c|c|c|}
\hline BELL. & & & & & & \\
\hline BUZZ. & & & & & & \\
\hline COMM & TEL. & TYPE. & & & & \\
\hline LITE. & TUBE. & WALL. & A/P. & & & \\
\hline HEAT. & OFF. & SLOW. & FAST. & LOW. & MED. & HIGH. \\
\hline RAD. & OFF. & T. & H. & L. & & \\
\hline VOL. & MIN. & 2. & 3. & 4. & MAX. & \\
\hline T.V. & OFF. & BBC.I. & ITV. I. & ITV. 2. & BBC.2. & \\
\hline VOL. & MIN. & 2. & 3. & 4. & MAX. & \\
\hline BRIL. & MIN. & 2. & 3. & 4. & MAX. & \\
\hline CON. & MIN. & 2. & 3. & 4. & MAX. & \\
\hline M.F.P. & ON. & & & & & \\
\hline TAPE. & OFF. & HOLD. & RECD. & P. B. & REW. & \\
\hline E.B. & OFF & LOW. & MED. & HIGH. & & \\
\hline RESP. & & & & & & \\
\hline I/C. & OFF & ALL. & KIT. & DWG.R. & BED.R. GDN. \\
\hline
\end{tabular}

Fig. 9

Plan of the indicator for a typical multi-purpose control system.

Some of the above controls are similar in operation to other useful functions, e.g. the control for the Micro-film Projector is entirely similar to that required for opening and closing the curtains or for adjusting the mirror position above a tank respirator. Similarly, the basic Electric Blanket control can be used to control the opening and closing of a door.

\section{POSSIBILITIES OF POSSUM IN THE INDUSTRIAL RESETTLEMENT OF TETRAPLEGICS}

Concurrent with the development in control of the patient's environment has gone on a consideration of the possibilities of his re-employment. The joint investi- 
gation into both the physiology of the residual control ability and the logical systems making use of his ability, indicated that the tetraplegic could be given work systems requiring sequential selection much more efficiently than those requiring complex three dimensional control. This distinction is commonly ignored or obscured in conventional Occupational Therapy practice. For instance it is frequently considered that typing (an example of sequential selection) is a more complex control problem than that of weaving (an example of complex three dimensional activity). Our systems can handle typing with ease but would fail at the handling of a free shuttle.

Control over a typewriter keyboard may be generalised to control over any suitable keyboard whatever the final functions which may be performed. Furthermore, control over a keyboard is a form of co-ordinate control and there is an increasing use of machine tools based on co-ordinate tables capable of being positioned with great accuracy beneath the tool, rather than move the tool to the workpiece. Such a machine tool has been adapted and is remarkable in that full control over its functions requires only some twenty choices, or speaking more conventionally-some 20 keys. The control problem is thus seen to be significantly less than that of a typewriter keyboard.

One of the equipments giving detailed control over the environment and one machine tool formed the basis for our exhibit at the Exhibition accompanying the Ninth Congress of the International Society for the Rehabilitation of the Disabled held at Copenhagen during the last week of June 1963. This exhibit won the Bell Greve Memorial Award for the most significant contribution to rehabilitation (fig. Io). A former tetraplegic patient, who sustained a fracture-dislocation of the fifth

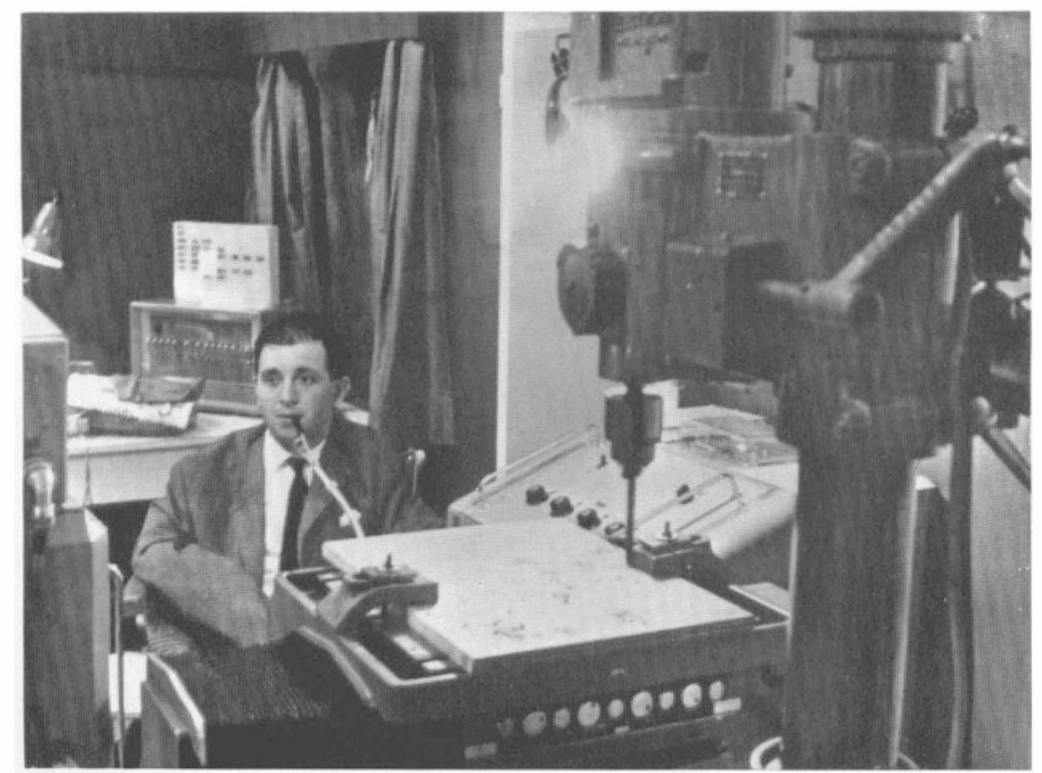

FIG. IO

Patient with high traumatic lesion of the cord controlling a power drill. 
cervical vertebra with tetraplegia after an accident at Rugby football in 1955, demonstrated at the Exhibition. He was remarkable both for the efficiency of his control ability and for his lucid explanation of the system whereby it was carried out. Prior to Copenhagen he had come back into the National Spinal Injury Centre, Stoke Mandeville, for a few weeks for practice sessions during mornings, afternoons and evenings and would frequently total io hours of concentrated activity in his wheelchair: We hope that this augurs well for the extension of tetraplegic's employment.

The work thus far may allow the generalisation that a Possum control can be constructed to match as its input the precise residual function of the disabled person, and as output any suitable electro-mechanical equipment.

The terms of reference of the project are to extend the Possum controls to all forms of severe disablement and congenital deformity and to all forms of suitable electro-mechanical, electronic, pneumatic and hydraulic equipment.

The Ministry of Health has agreed to a carefully planned trial of some twenty prototypes in various hospitals, institutions and private homes throughout the country. These are being paid for by the Polio Research Fund.

Present developments include:

I. The adaption of the control system to provide a wider range of functions. One of the more promising of these is the adaptation to the new cordless type telephone switchboard. This is simpler than a typewriter as a control problem and has the further advantage that in handling voices it is controlling a non-material medium. At the request of the Royal National Institute of the Blind we are considering such a system for a blind patient who is also a bilateral amputee.

2. The provision of a system of control over an electrically powered and steered wheelchair, for the higher cervical lesions unable to manage the existing systems, for instance, the 'Sleyride'.

3. An investigation into the control sites available from the various types of disablement and congenital deformity.

4. An investigation into the teaching methods required for the controls.

5. The application of patient controlled teaching machines for the education of the severely disabled.

Acknowledgments. We wish to acknowledge the splendid co-operation of Mr. Ian Pritchard and Mr. D. Hyde in demonstrating the Possum. To Dr. L. Guttmann we are indebted for the tremendous encouragement and advice from the start and helpful criticism of this paper. To the Polio Research Fund we are grateful for the generous grant to enable the development of this work.

\section{SUMMARY} detail.

I. A Patient Operated Selector Mechanism (Possum) has been described in

2. These mechanisms permit control over electro-mechanical devices by patients with high cord lesions or with extreme disability from other causes.

3. Any residual muscular power may be used for control but the mouth is preferred for the high cord lesions.

4. The research indicates that a high degree of control efficiency is possible. 
Systems now in use should permit control over typewriter and other keyboard devices at normal speeds.

5. Systems under consideration may permit the re-employment of such patients on a competitive industrial basis.

\section{RESUMÉ}

Un appareil de selection mécanique opperé par le malade (POSSUM) a été décrit d'une façon détaillé.

Cet appareil permet aux malades avec une atteinte haute de la moëlle épinière, ou avec de sévères infirmités, un contrôle d'appareils électro-mécaniques d'usage courrant. Tout ce qui reste de force musculaire peut être utilisé pour leur contrôle mais dans les lésions hautes de la moële épinière la bouche est preféree. Le travail de recherche montre qu'un très grand degré de contrôle est possible. Les systèmes utilisés a l'heure actuelle permettent l'utilisation de machines à écrire et d'autres mécaniques séléctifs similaires, à une vitesse normale.

D'autres systèmes, à l'étude, pourraient permettre le ré-emploit de tels malades sur un plan de competition industrielle.

\section{ZUSEMMENFASUNG}

Ein vom Patienten selbst controllierbarer Selector Mechanismus (POSSUM) ist in allen Einzelheiten beschrieben.

Dieser Mechanismus gestattet Patienten mit hohen Läsionen des Rückenmarks sowie andern schwersten körperlichen Behinderungen verschiedene elektro-mechanische Apparate $\mathrm{zu}$ bedienen.

Jegliche übrig gebliebene Muskelfunction kann für die Kontrolle gebraucht werden, aber in hohen Rückenmarksläsionen wird der Mund bevorzugt.

Versuche haben gezeigt, dass ein hoher Grad von Leistungsfähigkeit erzielt werden kann. Systeme augenblicklich in Gebrauch erlauben Kontrolle über eine Schreibmaschine und andere wichtige Apparate.

Specielle Apparaturen können in Zukunft die industrielle Wiedereingliedernug solcher Patienten ermöglichen. 